\title{
THE WENCKEBACH PHENOMENON ASSOCIATED WITH SIALORRHGA
}

\author{
BY
}

\author{
E. CHESLER AND L. SCHAMROTH \\ From the Baragwanath Hospital, Johannesburg
}

The Wenckebach phenomenon (1899) is a not uncommon form of partial A-V block and is usually associated with organic heart disease. Variations of this pattern have been described but are rare. We report here another variant of the Wenckebach phenomenon in a patient who complained only of sialorrhœa and showed no evidence of organic heart disease.

\section{Case Report}

A 23-year-old African male labourer stated that for the previous two years he had been troubled by periods of excessive salivation. These periods varied from a few days to several weeks with symptom-free intervals of similar duration. This excessive salivation necessitated the frequent use of a handkerchief, and on awakening, his pillow was often wet. There were no other symptoms. He had never experienced any syncopal attacks, nor was he prone to palpitations. He had no exertional dyspnœa and was able to complete a day of strenuous manual labour without discomfort. There was no history of rheumatic fever and he had not been taking drugs.

Physical examination showed a well nourished man. His blood pressure was 120/75 mm. Hg. Apart from occasional dropped beats detected at the pulse and on cardiac auscultation, there were no other abnormalities.

Full blood count and sedimentation rate were normal. C-reactive protein was absent.

Oral glucose tolerance curve showed a tendency to rebound hypoglycæmia: Fasting specimen-67 mg. per $100 \mathrm{ml}$. Post ingestion specimens: $\frac{1}{2}, 1,1 \frac{1}{2}, 2,3,3 \frac{1}{2}, 4,5,5 \frac{1}{2}$, and 6 hours were, 126, 160, 127, 105, 65, 43, $50,73,75$, and $77 \mathrm{mg}$. per $100 \mathrm{ml}$.

Teleradiogram and fluoroscopy revealed a normal heart shadow and normal lung fields.

Electrocardiograms showed the varying type of Wenckebach phenomenon (see Fig. 1, 2, and 3).

Complete relief of the sialorrhœa was afforded by the oral administration of tincture of belladonna, 10 minims thrice daily.

\section{Discussion}

In the classical Wenckebach type of A-V block the P-R interval shortens considerably after a beat is dropped and then lengthens progressively from cycle to cycle until conduction fails once again. A "reverse" Wenckebach phenomenon is described by Berman (1955). This consists basically of a $2: 1 \mathrm{~A}-\mathrm{V}$ block associated with decreasing $\mathbf{P}-\mathrm{R}$ intervals and ending in an occasional $\mathrm{I}: 1$ conducted beat with a prolonged $\mathbf{P}-\mathbf{R}$ interval: examples occurred as transient events in five patients, four of whom had posterior myocardial infarction and the other rheumatic carditis with aortic insufficiency. Furthermore, this arrhythmia was associated with a bad prognosis in the cases described. Another modification, reported by Scherf and Schott (1939) and Mack et al. (1947), was made up of a basic 1:1 conduction with diminishing P-R intervals ending in a nonconducted beat. Solinas and Sardo (1952) described fluctuations in the length of the P-R intervals which increase and decrease without dropped beats. Pallini et al. (1951) recorded a case in which the orderly progression of the Wenckebach pattern was interrupted by a short $\mathbf{P}-\mathbf{R}$ interval followed by a broad QRS complex of the Wolff-Parkinson-White type. In a case described by Simonson and Berman (1951), paroxysmal auricular tachycardia and partial A-V block were associated with diminishing P-R intervals. Segers (1951) recognized a 2:1 A-V block in which the P-R intervals of the conducted beats varied from $0 \cdot 14$ to $0 \cdot 21$ sec. 


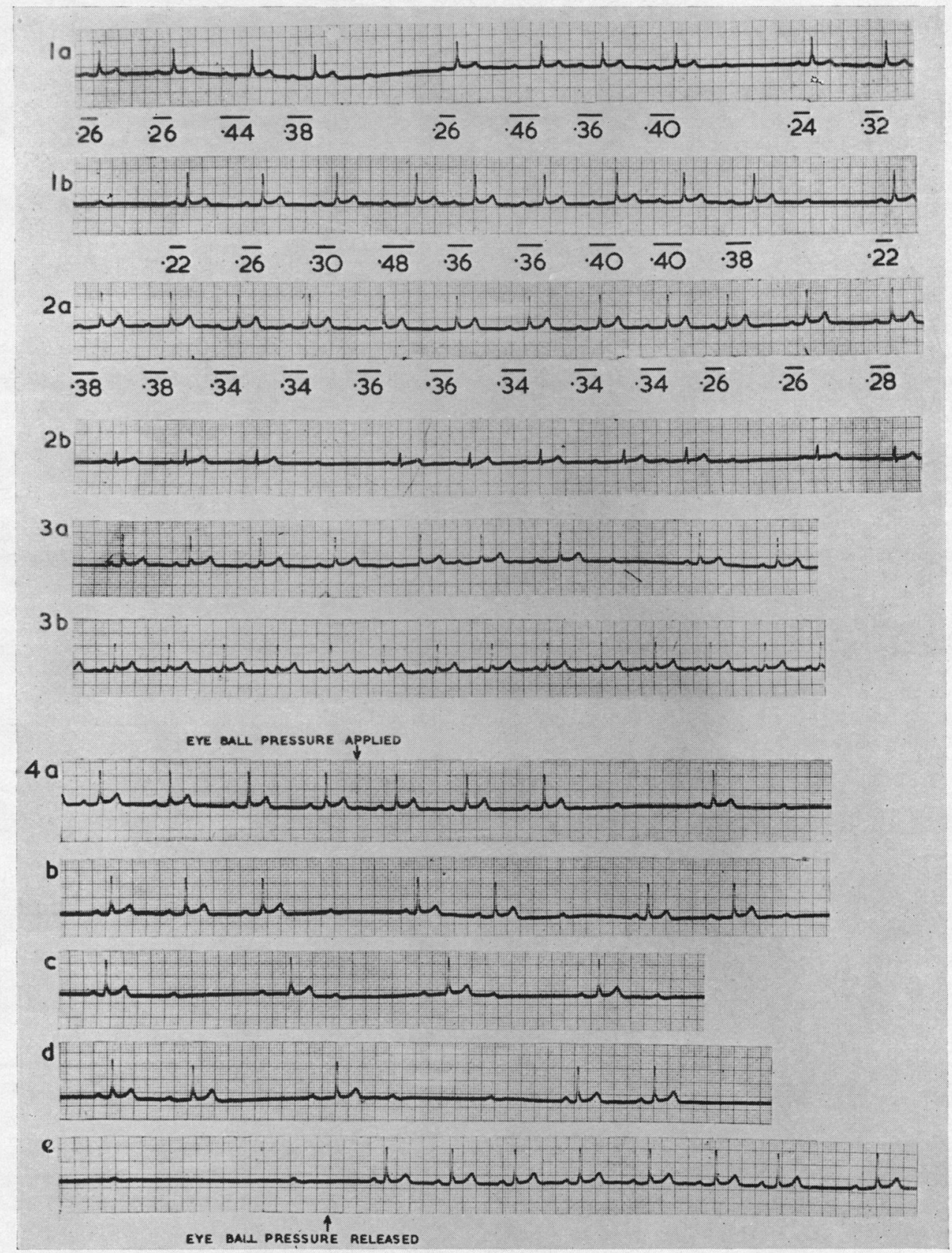

FIG. 1a: 7/3/56.-Standard lead II, showing the varying Wenckebach phenomenon, namely, varying P-R intervals with irregularly dropped beats (measured $P-R$ intervals indicated).

FIG. 1b: 10/7/56.-Standard lead II, showing the varying Wenckebach phenomenon (measured P-R interval indicated). FIG. 2a: 20/7/56.- Standard lead II: basic rhythm, showing minor variations in the P-R intervals without dropped beats as described by Solinas and Sardo. The normal sinus $\mathbf{P}$ waves are constant in shape and size (measured $\mathbf{P}-\mathbf{R}$ intervals indicated).

Fig. 2b: 20/7/56.-Lead AVF: The varying Wenckebach phenomenon induced by the intramuscular injection of $0.5 \mathrm{mg}$. prostigmine. This change occurred from the basic rhythm as shown in Fig. 2a.

FIG. 3a: 21/7/56. - Standard lead II, showing the varying Wenckebach phenomenon induced by carotid sinus pressure. 
Mobitz $(1924,1928)$ defined the Wenckebach phenomenon as Type I A-V block. His Type II A-V block, now known as the Mobitz block, consisted of irregularly dropped beats without previous lengthening of the $\mathbf{P}-\mathbf{R}$ interval.

The electrocardiogram of the case presented here shows some of the features of the classical Wenckebach phenomenon in that from an initially shorter $\mathbf{P}-\mathbf{R}$ interval, progressive lengthening occurs (Fig. 1a, 1b, 2b, and 3a). However, this progressive lengthening is not maintained, as $\mathbf{P}-\mathbf{R}$ intervals of shorter duration are interspersed. These variations in the $\mathbf{P}-\mathbf{R}$ intervals do not conform to any particular pattern and do not follow any logarithmic sequence. The dropped beat does not necessarily follow the cycle with the longest $\mathbf{P}-\mathrm{R}$ interval. The $\mathrm{P}-\mathrm{R}$ interval following the dropped beat is, however, always the shortest. This pattern was observed during episodes of sialorrhœa (Fig. 1a and $1 \mathrm{~b}$ ) and could be provoked by parasympathetico-mimetic measures such as eyeball pressure, carotid sinus pressure (Fig. 3a) and the injection of prostigmine (Fig. 2b). The dropped beats were easily abolished by the intravenous injection of atropine gr. 1/100 (Fig. 3b) although slight variations in the $\mathbf{P}-\mathbf{R}$ intervals were still evident. This increase and decrease in the $\mathbf{P}-\mathbf{R}$ intervals without dropped beats (as described by Solinas and Sardo) and with normal sinus $P$ waves of constant size and shape, was present as a basic abnormality (Fig. 2a). It was only with further increase in vagal tone occurring spontaneously during periods of sialorrhœa or as a result of the use of parasympathetico-mimetic measures that dropped beats reappeared. The effect of vagal stimulation is further demonstrated by the occurrence of S-A block, ventricular standstill, the classical Wenckebach phenomenon, and the "reverse" Wenckebach phenomenon with these measures (Fig. 4). Marked respiratory sinus arrhythmia was also observed.

The oral glucose tolerance curve showed a strong tendency towards rebound hypoglycæmia three and a half hours after the ingestion of $50 \mathrm{~g}$. glucose. This is due to an excess of postprandial insulin secretion from the action of a hypersensitive vagus as occurs in the vagotonic subject (Conn and Seltzer, 1955). The sialorrhœa is further evidence of this excessive vagal activity.

Partial heart block with dropped beats is almost invariably associated with organic disease. It is especially seen with digitalis intoxication, rheumatic and diphtheritic myocarditis, and coronary artery disease. An acute infection such as tonsillitis often precipitates it (Campbell, 1943). It has been produced experimentally by vagal stimulation (Mines, 1914; Lewis, 1925; Rothberger, 1931), and by parasympathetico-mimetic drugs (Starr, 1936; Dercherd and Ruskin, 1946). It may occur at low auricular rates under the influence of digitalis therapy, or at higher auricular rates as with paroxysmal auricular tachycardia.

A consideration of all the features of our case suggests that variations in vagal tone may well be the common factor affecting both excitability and conductivity, thus playing an important if not the dominant role in the mechanism of partial A-V block. This case illustrates the fact that gross cardiac arrhythmias are not characteristic of any specific clinical or pathological condition and may occur in the absence of organic heart disease. Furthermore, their presence does not invariably connote an adverse prognosis.

\section{Summary}

An unusual form of the Wenckebach type of partial A-V block is described.

Other rare varieties of partial A-V block were noted in the electrocardiograms of this patient.

These disorders of cardiac rhythm occurred in a man who showed evidence of excessive vagal activity but no signs of organic disease.

Legend to FIG. 3 continued.

FIG. 3b: 21/7/56.-Standard lead II: effect after the intravenous injection of 1/100 gr. of atropine sulphate, showing change to basic rhythm from the varying Wenckebach phenomenon as shown in Fig. 3a.

Fig. 4a to e: (continuous strip), 22/7/56.- Standard lead II: effect of eyeball pressure, showing the classical Wenckebach phenomenon (the last four complexes in Fig. 4b), an arrhythmia approximating to the Mobitz Type II block (the first three complexes in Fig. 4b), the "reverse" Wenckebach phenomenon as described by Berman (1955) (the last three complexes in Fig. $4 \mathrm{c}$ continued to the first two complexes in Fig. 4d), S-A block and also ventricular standstill (Fig. 4d and 4e). 
We wish to thank the Superintendent of Baragwanath Hospital for permission to publish this case. We acknowledge with thanks the helpful discussions with Dr. M. B. Schwartz and Dr. B. A. Bradlow. We are indebted to the Baragwanath Branch of the South African Institute for Medical Research for the laboratory investigations and to Mr. C. Shevitz of the University of the Witwatersrand, Department of Medicine for the photographic reproductions.

\section{References}

Berman, R. (1955). Amer. Heart J., 2, 211.

Campbell, M. (1943). Brit. Heart J., 5, 55.

Conn, T. W., and Seltzer, H. S. (1955). Amer. J. Med., 3, 460.

Dercherd, G. M., and Ruskin, A. (1946). Brit. Heart J., 8, 6.

Lewis, T. (1925). The Mechanism and Graphic Registration of the Heart Beat. Shaw and Sons, London.

Mack, I., Langendorf, R., and Katz, L. N. (1947). Amer. Heart J., 34, 374.

Mines, G. R. (1914). J. Physiol., 47, 419.

Mobitz, W. (1924). Z. ges. exp. Med., 41, 180. (1928). Z. klin. Med., 107, 456.

Pallini, C. A., Guidotti, M. P., and Violini, G. (1951). Atti. Soc. ital. Cardiol., 13, 357.

Rothberger, C. J. (1931). Ergebn. der Physiol., 32, 472.

Scherf, D., and Schott, A. (1939). Amer. Heart J., 17, 357.

Segers, M. (1951). Arch. Mal Coeur, 44, 525.

Simonson, E., and Berman, R. (1951). Amer. Heart J., 42, 387.

Solinas, L., and Sardo, S. L. (1952). Arch. Mal. Coeur., 45, 346.

Starr, I. (1936). J. Pharm. Exp. Ther., 56, 77.

Wenckebach, K. F. (1899). Z. klin. Med., 37, 475. 